\title{
Necrotizing fasciitis after scalpel injury sustained during postmortem examination
}

\author{
Michal Brichacek MD, Robert Strazar MD, Kenneth A Murray MD, Avinash Islur MD
}

Cite as: CMAJ 2017 May 23;189:E721-3. doi: 10.1503/cmaj.161386

A 44-year-old pathologist presented to the emergency department after sustaining a scalpel injury during a postmortem examination 16 hours previously. He had stabbed the dorsum of his left thumb overlying the interphalangeal joint and immediately irrigated the wound with water. At the time of presentation, he felt feverish, and had erythema and severe pain in his thumb. He was previously healthy, and did not smoke or have any known allergies. He was not taking any medications.

The patient was given ceftriaxone empirically in the emergency department, and the plastic surgery service was consulted. Upon examination, he was afebrile and had a $0.5-\mathrm{cm}$ laceration oriented obliquely over the dorsum of the interphalangeal joint of his thumb (Figure 1A). There was a hemorrhagic blister distal to the laceration and minimal purpuric discolouration around the laceration. Erythema tracked proximally to the metacarpophalangeal joint of the thumb, with lymphangitic streaking extending into the axilla. There was no impairment of range of motion of the thumb, no substantial pain and no tenderness on axial loading of the interphalangeal or metacarpophalangeal joints. There was no pain upon palpation over the flexor sheath or the volar deep spaces of the hand. However, there was substantial pain upon palpation over the dorsal thumb. A radiograph of the hand showed no abnormality other than swelling of soft tissue.

We suspected a localized subcutaneous infection and undertook a bedside incision and drainage. The hemorrhagic blister contained only blood and no pus. We extended the laceration overlying the interphalangeal joint and expressed a small amount of frank purulence. There was a $3 \mathrm{~mm}$ laceration in the extensor pollicis longus tendon overlying the interphalangeal joint, which communicated with the joint, but there was no purulence within the joint itself. The pus tracked proximally to the level of the metacarpophalangeal joint in a plane above the extensor pollicis longus tendon. We expressed all visible pus, irrigated copiously with $1 \mathrm{~L}$ of normal saline and packed the area with gauze. We continued to monitor the patient because of the rapid development of this infection and consulted the infectious diseases service.

We reassessed the patient two hours later and, although he remained afebrile with normal blood pressure,

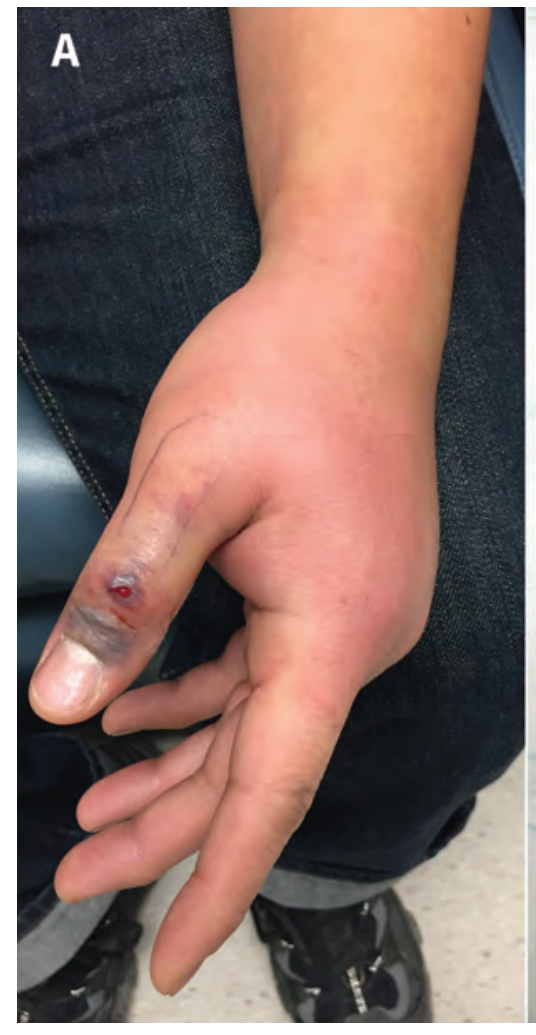

\section{KEY POINTS}

- Necrotizing fasciitis can occur in otherwise healthy individuals.

- Treatment involves emergency débridement in the operating theatre, broad spectrum antimicrobial drugs, local wound care and eventual free flap reconstruction .

- If the diagnosis is not clear, it is important to reassess the patient frequently and seek early expert advice in suspected cases.

- Imaging examination is ancillary and should never delay surgical treatment of necrotizing fasciitis.

Figure 1: View of the left thumb of a 44-year-old pathologist after injury caused by a scalpel blade during a postmortem examination. Initial presentation showed purpuric skin changes to the dorsum of the thumb distal to the interphalangeal (IP) joint, a small stab incision overlying the IP joint and slight erythema to the dorsum of the hand (A). Two hours after initial presentation, there was progression of purpuric skin changes, markedly increased erythema and swelling of the hand (B). 


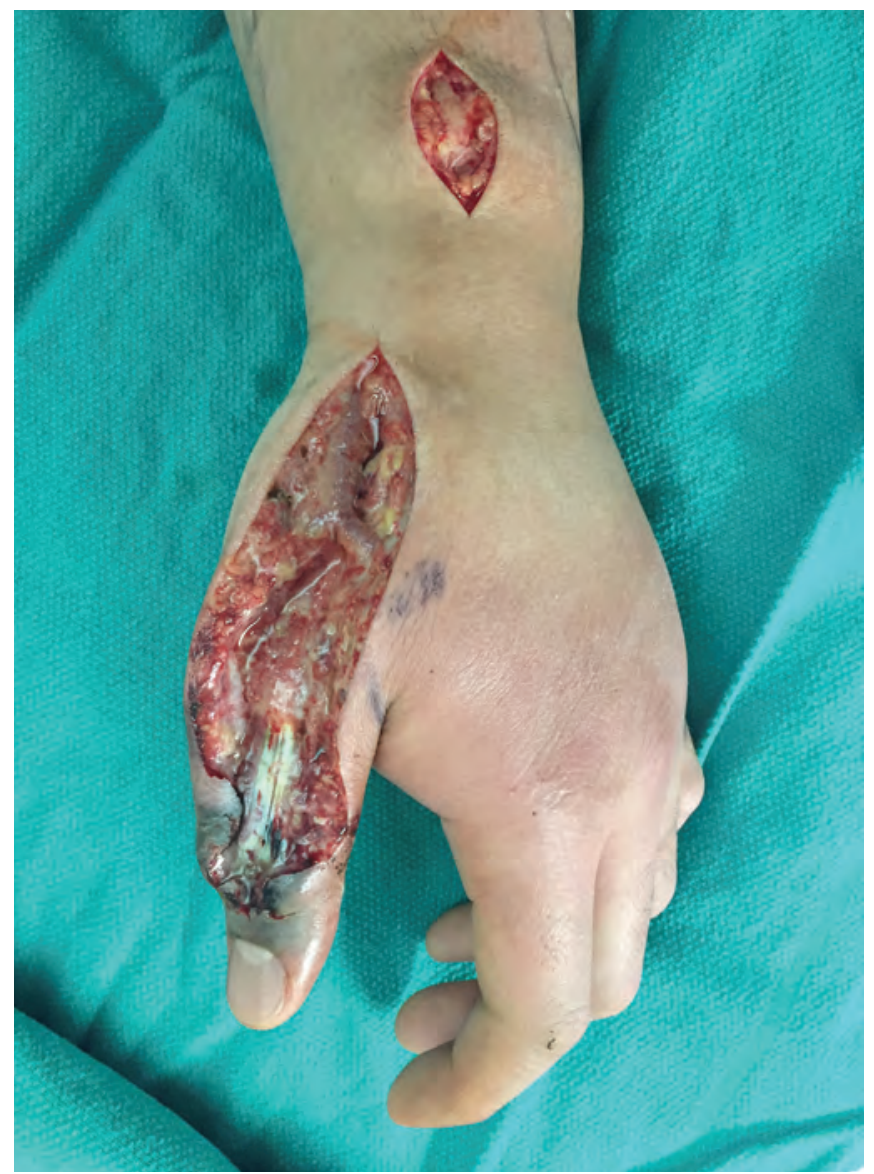

Figure 2: View showing the incision and drainage that was performed in the operating theatre, with extension of the incision proximally along the dorsum of the thumb. Frank purulence was found to track along the fascia overlying the extensor pollicis longus tendon to the level of the wrist crease dorsally, with the fascia in multiple areas appearing nonviable.

he had a sinus tachycardia (heart rate 131 beats/min). Results from bloodwork showed an elevated leukocyte count of $20.8 \times 10^{9} / \mathrm{L}$ with left shift (neutrophils $84 \%$ ), and his platelet count was $170 \times 10^{9} / \mathrm{L}$. Erythema had progressed past our previous markings to involve the entire hand, and lymphangitic streaking had also advanced. His pain had increased and the area of purpura surrounding the initial laceration had progressed (Figure 1B). Given this rapid change, the patient was taken to the operating theatre for urgent incision and débridement of suspected necrotizing fasciitis.

We extended the incision proximally along the dorsum of the thumb. We found pus tracking along the fascia overlying the extensor pollicis longus tendon to the level of the wrist crease dorsally. The fascia appeared nonviable in many areas, and the distal skin overlying the interphalangeal joint also appeared nonviable (Figure 2). The entire wound, including the communication into the interphalangeal joint, was pulse irrigated with $5 \mathrm{~L}$ of normal saline. We did not remove any skin in the hope that it might remain viable.

Postoperatively, the patient was given intravenous ceftriaxone, clindamycin and vancomycin as recommended by the infectious diseases service. Results from a plasma lactate test drawn one hour postoperatively were normal. Dressings were changed three times daily, and the infection progressively improved. Box 1 illustrates the timeline.
Box 1: Timeline of events and interventions undertaken for the care of a patient with an injury from a scalpel blade

\begin{tabular}{|c|c|}
\hline Timeline & Event/intervention \\
\hline \multicolumn{2}{|c|}{ Day of injury } \\
\hline $14: 00$ & Patient sustains scalpel injury \\
\hline \multicolumn{2}{|c|}{ Postinjury day one } \\
\hline 05:48 & Patient presents to triage at emergency department \\
\hline $08: 18$ & $\begin{array}{l}\text { - Patient assessed by emergency department physician } \\
\text { - Plastic surgery consulted for possible tenosynovitis }\end{array}$ \\
\hline 08:39 & Patient given ceftriaxone ( $2 \mathrm{~g}$ intravenously) \\
\hline 11:06 & $\begin{array}{l}\text { - Patient first assessed by plastic surgery service } \\
\text { - Initial incision and drainage performed } \\
\text { - Infectious disease consultation suggested }\end{array}$ \\
\hline $14: 04$ & $\begin{array}{l}\text { - Patient assessed by infectious diseases service } \\
\text { - Substantial progression of infection a concern for } \\
\text { necrotising fasciitis } \\
\text { - Suggested addition of vancomycin and clindamycin }\end{array}$ \\
\hline $14: 13$ & Vancomycin (1 g intravenously) \\
\hline $14: 32$ & Clindamycin (600 mg intravenously) \\
\hline $14: 48$ & $\begin{array}{l}\text { - Patient reassessed by plastic surgery service } \\
\text { - Substantially worsened appearance } \\
\text { - Decision made to take to operating room }\end{array}$ \\
\hline $16: 07$ & Surgery begins for incision and drainage of infection \\
\hline $17: 14$ & Clindamycin (600 mg intravenously) \\
\hline $21: 06$ & $\begin{array}{l}\text { - Wounds reassessed by plastic surgery service } \\
\text { - Erythema markedly reduced from last marking } \\
\text { - Minimal tenderness } \\
\text { - No purulence or malodour from wounds }\end{array}$ \\
\hline
\end{tabular}

\section{Postinjury day two}

$\begin{array}{ll}\text { 03:21 } & \text { Vancomycin (1 g intravenously) } \\ \text { 06:30 } & \text { Clindamycin (600 mg intravenously) } \\ \text { 09:00 } & \text { Ceftriaxone (2 g intravenously) } \\ \text { 13:53 } & \text { Clindamycin (600 mg intravenously) } \\ \text { 15:44 } & \text { Vancomycin (1 g intravenously) } \\ \text { 18:00 } & \text { Penicillin G (4 million units intravenously) } \\ \text { 22:15 } & \text { Clindamycin (600 mg intravenously) } \\ \text { 23:28 } & \text { Penicillin G (4 million units intravenously) }\end{array}$

Subsequently, swabs of the wound grew group A $\beta$-hemolytic streptococcus. Based on these results, we stopped treatment with vancomycin on postoperative day 2 , and the patient was given penicillin $\mathrm{G}$ and clindamycin, both of which were stopped on postoperative day 5. Because of a concern about possible bacterial joint seeding, the infectious diseases service recommended that we continue treatment with ceftriaxone for three weeks.

By postoperative day 5, an area of skin tissue $\left(1.5 \times 1.5 \mathrm{~cm}^{2}\right)$ overlying the dorsal interphalangeal joint was nonviable and required débridement. Because the tendon was exposed, we performed delayed primary wound closure with local skin flaps on postoperative day 6 . This ultimately broke down and required reconstruction using a fascial anterior lateral thigh free flap covered by a split thickness skin graft (Figure 3). 


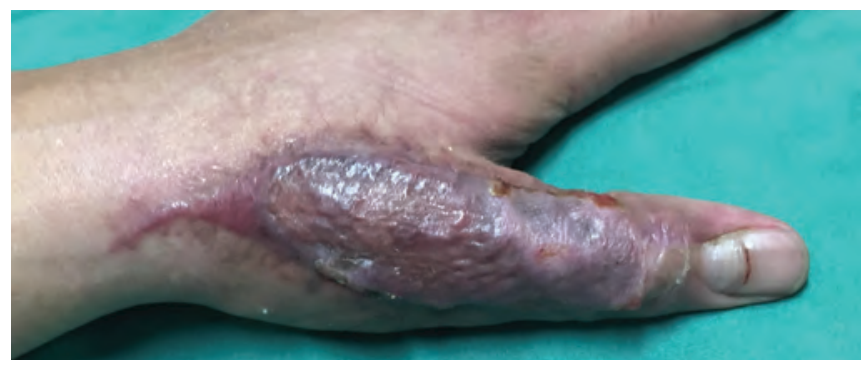

Figure 3: View showing the reconstructed defect six weeks after the operation. After the initial closure had broken down and exposed the interphalangeal joint, a fascial anterior lateral thigh free flap covered with a split thickness skin graft was used to reconstruct the defect.

\section{Discussion}

The literature is unclear regarding advice on the care of acute wounds, in particular wound cleansing. ${ }^{1}$ There is no evidence that irrigation with water is helpful in reducing infection, although this remains the standard of care. ${ }^{2}$ Similarly, there is no evidence favouring the use of disinfectants rather than water. ${ }^{1}$

Disease arising from accidental injury caused by scalpels is not a novel phenomenon. Modern day antiseptic technique was pioneered by Dr. Ignaz Philipp Semmelweis after a similar accidental scalpel injury occurred to his colleague Dr. Jakob Kolletschka. ${ }^{3}$ Kolletschka was struck accidently by a student's scalpel during a postmortem examination, which led to his death. Semmelweis noted that Kolletschka showed similar pathologic findings to many women in his hospital who had died of puerperal fever. He proposed that puerperal fever was contagious and that appropriate handwashing by medical caregivers could substantially decrease its incidence. ${ }^{3}$

Injuries caused by scalpels are not uncommon among health care workers. ${ }^{4}$ Although infrequent, transmission of diseases such as syphilis, cutaneous tuberculosis and HIV has been described. ${ }^{5}$ Nosocomial transmission of invasive group A streptococcus also has been reported, but progression to fulminant disease among health care workers is rare. A case of streptococcal toxic shock syndrome in a respiratory therapist that resulted from an apparent transmission from a patient with group A streptococcus infection has been reported. ${ }^{5}$ Necrotizing fasciitis was described following a scalpel blade injury in a nurse who cut herself during débridement, but she did not develop systemic symptoms and was taken to the operating room after 14 days. ${ }^{6}$ In our case, the body undergoing postmortem examination had no history of necrotizing fasciitis, but no tests for group $A \beta$-hemolytic streptococcus had been undertaken.

Dr. Joseph Jones, a Confederate Army surgeon, is credited with providing the first modern description of necrotizing fasciitis in $1869 .^{7}$ It is an uncommon, rapidly progressive and life-threatening infection that requires urgent medical and surgical treatment. Individuals who are particularly susceptible include those with diabetes mellitus, intravenous drug users and those who are immunocompromised. ${ }^{7}$ However, these infections can arise in people who are healthy. ${ }^{7}$

Proliferation of a microbial pathogen in the deep fascial plane results in thrombosis of the local microcirculation and rapid ischemic necrosis of the overlying subcutaneous tissues. ${ }^{8}$ This is characteristically associated with presentation of septic shock, severe pain in the affected area and various clinical signs, such as violaceous discolouration of the skin, skin necrosis, hemorrhagic bullae and crepitus. ${ }^{9}$

Diagnosis may be challenging as there are no distinct identifying signs. Scoring systems such as the Laboratory Risk Indicator for Necrotizing Fasciitis (LRINEC) score were developed to aid early recognition; ${ }^{10}$ however, necrotizing fasciitis has been identified in cases with a LRINEC score of $0 .{ }^{9}$ It is important to be clinically alert to the condition, regardless of LRINEC scores, and to seek early expert advice when necrotizing fasciitis is suspected. ${ }^{9}$

Magnetic resonance imaging (MRI) has been studied extensively as an aid to diagnosis but its use remains controversial. ${ }^{8}$ Although the absence of deep fascial involvement on MRI effectively excludes necrotizing fasciitis, other findings are nonspecific and may lead to overor underdiagnosis. ${ }^{8}$ Although MRI is a useful modality, it has an ancillary role and should never delay surgical treatment; positive outcomes depend on prompt and appropriate therapy. ${ }^{10}$ In cases where the diagnosis is not clear, frequent reassessment is the key to identifying rapid progression. In this case, it was the short time for development of substantial infection that alerted us.

This case, although uncommon, is a reminder that even a minor scalpel injury can result in a life-threatening infection. Substantial cutaneous infections that progress over a short period of time should alert clinicians to necrotizing fasciitis. Patients should be reassessed frequently, expert advice should be sought early on and imaging should not delay surgical treatment.

\section{References}

1. Ubbink DT, Brolmann FE, Go PM, et al. Evidence-based care of acute wounds: a perspective. Adv Wound Care (New Rochelle) 2015;4:286-94.

2. Fernandez R, Griffiths R. Water for wound cleansing. Cochrane Database Syst Rev 2012;(2)CD003861.

3. Semmelweis IP. Childbed fever. Rev Infect Dis 1981;3:808-11. Available: www. jsor.org/stgable/4452613 (accessed 2017 Feb. 22).

4. Watt AM, Patkin M, Sinnott MJ, et al. Scalpel injuries in the operating theatre. BMJ 2008;336:1031.

5. Lacy MD, Horn K. Nosocomial transmission of invasive group A streptococcus from patient to health care worker. Clin Infect Dis 2009;49:354-7.

6. Sablier F, Slaouti T, Dreze PA, et al. Nosocomial transmission of necrotising fasciitis. Lancet 2010;375:1052.

7. Quirk WF Jr, Sternbach G. Joseph Jones: infection with flesh eating bacteria. J Emerg Med 1996;14:747-53.

8. Arslan A, Pierre-Jerome C, Borthne A. Necrotizing fasciitis: unreliable MRI findings in the preoperative diagnosis. Eur J Radiol 2000;36:139-43.

9. Wilson MP, Schneir AB. A case of necrotizing fasciitis with a LRINEC score of zero: clinical suspicion should trump scoring systems. J Emerg Med 2013;44:928-31.

10. Wong $\mathrm{CH}$, Khin LW, Heng KS, et al. The LRINEC (Laboratory Risk Indicator for Necrotizing Fasciitis) score: a tool for distinguishing necrotizing fasciitis from other soft tissue infections. Crit Care Med 2004;32:1535-41.

\section{Competing interests: None declared.}

This article has been peer reviewed.

The authors have obtained patient consent.

Affiliation: Section of Plastic Surgery, Department of Surgery, University of Manitoba, Winnipeg, Man.

Contributors: All of the authors contributed to the conception and design of the manuscript, revised it critically for important intellectual content, approved the final version to be published and agreed to be accountable for all aspects of the work.

Correspondence to: Avinash Islur, aislur@mymts.net 